\title{
ARGINASE INHIBITORY ACTIVITY OF STEM BARK EXTRACTS OF CAESALPINIA TORTUOSA ROXB
}

\author{
AMIRAH NAJID, BERNA ELYA*, ARIKADIA NOVIANI
}

Department of Phytochemical and Pharmacognosy, Faculty of Pharmacy, Universitas Indonesia, Depok, 16424, Indonesia. Email: berna.elya@farmasi.ui.ac.id

Received: 14 June 2018, Revised and Accepted: 15 September 2018 and 24 October 2018

\section{ABSTRACT}

Objective: This study aimed to evaluate the arginase inhibitory activity of Caesalpinia tortuosa Roxb. stem bark extracts.

Methods: C. tortuosa Roxb. stem bark extracts were obtained through reflux extraction using n-hexane, ethyl acetate, and methanol and their inhibitory activity against arginase was measured using a microplate reader at $430 \mathrm{~nm}$. Active extracts were subjected to phytochemical analysis and based on the qualitative phytochemical analysis, quantitative data regarding flavonoid and phenolic contents were obtained. The total flavonoid content of active extracts was determined using $\mathrm{AlCl}_{3}$ colorimetric method, and the phenolic content was determined using Folin-Ciocalteu method.

Results: Ethyl acetate and methanol extracts of $C$. tortuosa Roxb. inhibited activity of arginase with $\mathrm{IC}_{50}$ values of 33.81 and $11.58 \mu \mathrm{g} / \mathrm{mL}$, respectively, nor-NOHA acetate as standard drug inhibited arginase with $\mathrm{IC}_{50}$ values of $\mathrm{I} 3.77 \mu \mathrm{g} / \mathrm{mL}$. Both active extracts contained saponins, tannins, and flavonoids. Ethyl acetate and methanol extracts showed a total flavonoid content of $7.41 \mathrm{mgQE} / \mathrm{g}$ and $5.05 \mathrm{mgQE} / \mathrm{g}$ and total phenolic content of $27.55 \mathrm{mgGE} / \mathrm{g}$ and $17.16 \mathrm{mgGE} / \mathrm{g}$, respectively. Methanol extracts had a higher inhibitory activity than ethyl acetate extracts despite having flavonoid and phenolic content, thereby suggesting no correlation between arginase inhibitory activity and flavonoid or phenolic content.

Conclusion: Ethyl acetate and methanolic extracts of $C$. tortuosa Roxb. stem barks containing flavonoids, tannins, and saponins displayed arginase inhibitory activity, and no correlation was observed between arginase inhibitory activity and flavonoid and phenolic content.

Keywords: Caesalpinia tortuosa, Arginase inhibition, Phytochemical screening, Total flavonoids, Total phenolics

(C) 2018 The Authors. Published by Innovare Academic Sciences Pvt Ltd. This is an open access article under the CC BY license (http://creativecommons. org/licenses/by/4. 0/) DOI: http://dx.doi.org/10.22159/ijap.2018.v10s1.27

\section{INTRODUCTION}

Caesalpinia tortuosa Roxb., Leguminosae, which is endemic to the Asian region (India, Myanmar, Burma, China, Malaysia, and Singapore), has been mostly found in Indonesia, particularly in Sumatra, Java, and Kalimantan [1,2]. The genus Caesalpinia has more than 500 species, each of which has several benefits for humans [3]. Such benefits include their use as dyes, preservatives, astringents, antioxidants, antibacterial agents, antiinflammatory agents, antimalarial agents, fat reduction agents, vasodilators, liver protectants, wound healing agents, anticancer agents, antidiabetic agents, antirheumatic agents, anti-acne agents, antiatherosclerotic agents, antineoplastic agents, and immunostimulants [3]. Bioactive compounds derived from Caesalpinia include flavonoids, polyphenols, saponins, diterpenes, triterpenes, naphthoquinones, peltoginoids, chalcone, steroids, gallic acid, tannic acid, tannins, resins, resorcin, brasilien, d-alphaphellandrene, oscimin, and several essentials oil $[3,4]$. Based on previous studies, numerous phytochemical compounds, such as polyphenols [5], flavonoids [6], flavanones [7], flavonols, quercetin [8], and quercitrin [9,10], have shown to exhibit arginase inhibitory activity. Moreover, phytochemical studies on Caesalpinia ferrea stem barks have revealed the presence of flavonoids, saponins, tannins, coumarin, steroids, and phenolic compounds and gallic acid, catechins, epicatechins, and ellagic acid [11,12]. A study performed on ethyl acetate and methanol extracts from $C$. sappan L. lignum showed an arginase inhibition with IC50 of 98.7 and $132.02 \mu \mathrm{g} / \mathrm{mL}$, respectively [8]. Another study on ethyl acetate extracts from $C$. sappan L. lignum has reported an IC50 of $36.8 \mu \mathrm{g} / \mathrm{mL}$ [8].

Arginase (l-arginine ureahydrolase or amidino hydrolase) is a hydrolysis enzyme that converts l-arginine to ornithine and urea. During pathological conditions, the level of arginase may increase, resulting in direct competition with endothelial nitric oxide synthase (eNOS) for l-arginine, which is another substrate for arginase. High levels of arginase deplete substrates for eNOS; thereby disturbing NO production impaired NO balance in the body causes impaired vascular endothelial function [13]. Studies on ethyl acetate extracts from $C$. sappan lignum have demonstrated arginase inhibitory activity, increased NO production, decreased reactive oxygen species production, and improved eNOS dimer stability in cultured human umbilical vein endothelial cells and aortic endothelial cells from mice [8]. Therefore, the present study aimed to determine the arginase inhibitory activity of C. tortuosa Roxb. stem bark extracts.

\section{METHODS}

\section{Preparation of extracts}

About $150 \mathrm{~g}$ of powder underwent successive multilevel reflux extraction at $80^{\circ} \mathrm{C}$ with $\mathrm{n}$-hexane, ethyl acetate, and methanol from low to high solvent polarity for three cycles. The solution was filtered using a $0.45-\mu \mathrm{m}$ membrane filter, and the filtrate was concentrated using a water bath.

\section{Arginase inhibition assay}

In vitro arginase inhibition assay was performed using a microplate reader at $430 \mathrm{~nm}$ using nor-NOHA acetate as the standard drug.

\section{Substrate optimization}

Substrate optimization was performed using concentrations of $130,570,650$, and $820 \mathrm{mM}$ as suggested by the protocol. Substrate concentrations were tested using $1 \mathrm{U} / \mathrm{mL}$ of arginase enzyme. The procedure was performed in triplicate using $10 \mu \mathrm{L}$ of bidistillation water, $15 \mu \mathrm{l}$ of enzyme solution, and $20 \mu \mathrm{l}$ of substrate solution followed by incubation for $30 \mathrm{~min}$ at $37^{\circ} \mathrm{C}$. After incubation, $100 \mu \mathrm{l}$ of urea was directly added, followed by incubation at room temperature $\left(25^{\circ} \mathrm{C}\right)$. 
Arginase inhibition of nor-NOHA acetate

Nor-NOHA acetate is a potential inhibitor of arginase. Concentrations of $0.5,1,3,4$, and $5 \mu \mathrm{g} / \mathrm{mL}$ of nor-NOHA acetate were used included in wells based on the IC50 range required by the protocol provided by Sigma-Aldrich ${ }^{\circledR}$.

\section{Arginase inhibition of samples}

Using procedure as mentioned before, $100 \mu \mathrm{g} / \mathrm{mL}$ of $\mathrm{n}$-hexane, ethyl acetate, and methanol extracts was prepared in wells to screen for active extracts. Active extracts were tested using five concentrations to determine the IC50 value based on potential screening.

\section{Qualitative phytochemical analysis}

Extracts underwent phytochemical analysis to determine the presence of alkaloids, flavonoids, tannins, saponins, quinones, and triterpenoids according to common method performed by Farnsworth $[2,14]$.

\section{Quantitative phytochemical analysis}

\section{Determination of total flavonoid content}

Total flavonoid content was determined using $\mathrm{AlCl}_{3}$ colorimetric method. $0.5 \mathrm{~mL}$ of ethyl acetate and methanol extracts, $1.5 \mathrm{~mL}$ of ethanol pro-analysis, $0.1 \mathrm{~mL}$ of $10 \% \mathrm{AlCl}_{3}, 0.1 \mathrm{~mL}$ of $1 \mathrm{M}$ potassium acetate, and $2.8 \mathrm{~mL}$ of distilled water were added to each test tube. All test tubes were incubated at room temperature for $30 \mathrm{~min}$. Absorbance

Table 1: Results of multilevel extraction

\begin{tabular}{lll}
\hline Extract & Weight (g) & Yield (\%) \\
\hline$n$-hexane & 1.02 & 0.68 \\
Ethyl acetate & 2.58 & 1.72 \\
Methanol & 13.45 & 8.96 \\
\hline
\end{tabular}

Table 2: Arginase inhibition of the ethyl acetate extract

\begin{tabular}{lll}
\hline $\begin{array}{l}\text { Ethyl acetate extract in } \\
\text { wells }(\boldsymbol{\mu g} / \mathbf{m L})\end{array}$ & \% Inhibition $(\%)$ & $\mathbf{I C}_{\mathbf{5 0}}(\boldsymbol{\mu g} / \mathbf{m L})$ \\
\hline 20 & $35.75 \pm 4.934$ & 33.812 \\
50 & $67.69 \pm 7.283$ & \\
70 & $76.11 \pm 1.704$ & \\
90 & $82.05 \pm 2.417$ & \\
100 & $89.37 \pm 5.273$ & \\
\hline
\end{tabular}

Table 3: Arginase inhibition of the methanol extract

\begin{tabular}{lll}
\hline $\begin{array}{l}\text { Methanol extract in } \\
\text { wells }(\mu \mathrm{g} / \mathrm{mL})\end{array}$ & \% Inhibition (\%) & IC $_{\mathbf{5 0}}(\boldsymbol{\mu g} / \mathbf{m L})$ \\
\hline 10 & $50.79 \pm 3.975$ & 11.58 \\
20 & $54.63 \pm 5.833$ & \\
70 & $66.59 \pm 5.151$ & \\
90 & $78.20 \pm 11.162$ & \\
100 & $92.21 \pm 4.271$ & \\
\hline s, the $\mathrm{IC}_{50}$ values of ethyl acetate and methanol extracts were 33.812 and \\
$11.58 \mu \mathrm{g} / \mathrm{mL}$, respectively
\end{tabular}

was measured at $437.5 \mathrm{~nm}$. Quercetin was used as a standard to create a calibration curve. The total flavonoid content in the extracts was calculated in triplicate, after which mean values were presented.

\section{Determination of total phenolic content}

The total phenolic content was assessed using the Folin-Ciocalteu method. Briefly, $1 \mathrm{~mL}$ of sample $(100 \mu \mathrm{g} / \mathrm{mL})$ was mixed with $0.5 \mathrm{~mL}$ of Folin-Ciocalteu reagent and $4 \mathrm{~mL}$ of $1 \% \mathrm{NaOH}$. The reaction mixture was incubated at $25^{\circ} \mathrm{C}$ for $1 \mathrm{~h}$, and the absorbance of the mixture was read at $730 \mathrm{~nm}$. The sample was tested in triplicate, and a calibration curve with six data points for gallic acid was obtained. Results were compared using the gallic acid calibration curve, and the total phenolic content of $C$. tortuosa Roxb. extracts was expressed as mg of gallic acid equivalents (GE) per $100 \mathrm{~g}$ of extract.

\section{RESULTS AND DISCUSSION}

Reflux extraction was considered based on the efficiency of the method employing a reduction in extractant viscosity, which increases the solvent's ability to penetrate into the sample matrix. The use of different solvent polarities allows for varying dispersibility and penetrability, such that phytochemical components can be selectively identified $[15,16]$. Extraction temperature was set below $80^{\circ} \mathrm{C}$ to minimize the degradation of flavonoid and phenolic compounds [17], the results of extraction are shown in Table 1.

\section{Arginase inhibition assay}

After optimization, the optimum level of l-arginine substrate was determined to be $570 \mathrm{mM}$ at an arginase concentration of $1 \mathrm{U} / \mathrm{mL}$. Moreover, according to the standard assay, the IC50 value for norNOHA acetate was determined to be $3.77 \mu \mathrm{g} / \mathrm{mL}$ ( $\mathrm{y}=4.8755 \mathrm{x}+31.604$, $r=0.9749$ ). Nor-NOHA acetate was selected for this assay because it exhibits the most potential arginase inhibitory activity compared with that of other standard compounds, such as NOHA and boronic acid [13].

Extracts to be assayed were prepared by diluting them with Aquabidest and dimethyl sulfoxide. A dimethyl sulfoxide concentration of $0-0.4 \%$ was used to avoid significant effects of UV absorption [18]. Accordingly, potential inhibition from n-hexane, ethyl acetate, and methanol extracts were $48.68 \%, 88.39 \%$, and $92.21 \%$, respectively. IC50 values were calculated for ethyl acetate and methanol extracts with $>50 \%$ potential inhibition, and these values presented in Tables 2 and 3, respectively.

\section{Qualitative phytochemical analysis}

Results of the phytochemical analysis are presented in Table 4.

Table 4 shows that ethyl acetate and methanol extracts contained saponins, tannins, and flavonoids.

\section{Quantitative phytochemical analysis \\ Determination of the total flavonoid content}

The calibration curve for quercetin showed maximum absorbances at $437.5 \mathrm{~nm}\left(\mathrm{y}=0.0774 \mathrm{x}+0.0035, \mathrm{r}^{2}=0.9994\right)$. The total flavonoid content of ethyl acetate and methanol extracts was 7.41 and $5.052 \mathrm{mgQE} / \mathrm{g}$, respectively.

Table 4: Phytochemical analysis of C. tortuosa Roxb.

\begin{tabular}{|c|c|c|c|}
\hline Phytochemical & Reagent & Ethyl acetate & Methanol \\
\hline \multirow[t]{3}{*}{ Alkaloids } & Dragendorff & - & - \\
\hline & Mayer & - & - \\
\hline & Wagner & - & - \\
\hline Flavonoids & Mg, HCl: EtOH (1:1) + amyl alcohol & +++ & ++ \\
\hline \multirow[t]{2}{*}{ Tannins } & Gelatin & ++ & +++ \\
\hline & $\mathrm{FeCl}_{3} 10 \%$ & +++ & +++ \\
\hline Saponins & Froth test & ++ & +++ \\
\hline Triterpenoids & $\mathrm{EtOH}+$ diethyl ether+concentrated $\mathrm{H}_{2} \mathrm{SO}_{4}+\mathrm{CH}_{3} \mathrm{COOH}$ anhydrous & - & - \\
\hline
\end{tabular}




\section{Determination of the total phenolic content}

The calibration curve for gallic acid showed maximum absorbances at $730 \mathrm{~nm}\left(\mathrm{y}=0.0076 \mathrm{x}+0.1486, \mathrm{r}^{2}=0.9958\right)$. The total phenolic content of active ethyl acetate and methanol extracts was 27.553 and 17.158 $\mathrm{mgGE} / \mathrm{g}$, respectively.

Considering that the methanol extract had the highest arginase inhibitory activity despite having lesser flavonoid and phenolic content than the ethyl acetate extract, our results revealed no correlation between arginase inhibitory activity and flavonoid and phenolic content, which is consistent with findings of previous studies.

\section{CONCLUSION}

Our study findings suggested that methanol extracts from $C$. tortuosa Roxb. stem barks have the greatest potential for arginase inhibition. Moreover, ethyl acetate extracts had the highest total flavonoid and phenolic content. Both active ethyl and methanol extracts contained saponins, tannins, and flavonoids. Finally, no correlation between arginase inhibitory activity and flavonoids and phenolics content was observed.

\section{ACKNOWLEDGMENTS}

All authors acknowledge Universitas Indonesia for support and PITTA Research Grants 2017.

\section{CONFLICTS OF INTEREST}

All authors have none to declare.

\section{REFERENCES}

1. Chadburn H. Caesalpinia Tortuosa. The IUCN Red List of Threatened Species 2012: e.T19892394A20034138;2012.Available from: http://www. dx.doi.org/10.2305/IUCN.UK.2012.RLTS.T19892394A2003 4138.en. [Last accessed on $14 \mathrm{Jul} 2018$ ].

2. Farnsworth NR. Biological and phytochemical screening of plants. J Pharm Sci 1966;55:225-76

3. Zanin JL, de Carvalho BA, Martineli PS, dos Santos MH, Lago JH, SartorelliP, et al. The genus Caesalpinia L. (Caesalpiniaceae): Phytochemical and pharmacological characteristics. Molecules 2012;17:7887-902.

4. Rina O, Ibrahim S, Dharma A, Afrizal, Chandra UW, Widodo YR Stabilities natural colorant of sappan wood (Caesalpinia sappan L.) for food and beverages in various $\mathrm{pH}$, temperature, and matrices of food. Int J Chem Tech Res 2017;10:98-103.
5. Oboh G, Ademiluyi AO, Ademosun AO, Olasehinde TA, Oyeleye SI, Boligon AA, et al. Phenolic extract from Moringa oleifera leaves inhibits key enzymes linked to erectile dysfunction and oxidative stress in rats 'penile tissues. Biochem Res Int 2015;2015:175950.

6. Glisic S, Sencanski M, Perovic V, Stevanovic S, García-Sosa AT. Arginase flavonoid anti-leishmanial in silico inhibitors flagged against anti-targets. Molecules 2016;21:589.

7. Kim SW, Cuong TD, Hung TM, Ryoo S, Lee JH, Min BS, et al. Arginase II inhibitory activity of flavonoid compounds from Scutellaria indica. Arch Pharm Res 2013;36:922-6.

8. Shin W, Cuong TD, Lee JH, Min B, Jeon BH, Lim HK, et al. Arginase inhibition by ethylacetate extract of Caesalpinia sappan lignum contributes to activation of endothelial nitric oxide synthase. Korean J Physiol Pharmacol 2011;15:123-8.

9. da Silva ER, Maquiaveli Cdo C, Magalhães PP. The leishmanicidal flavonols quercetin and quercitrin target Leishmania (Leishmania) amazonensis arginase. Exp Parasitol 2012;130:183-8.

10. Schnorr O, Brossette T, Momma TY, Kleinbongard P, Keen CL, Schroeter $\mathrm{H}$, et al. Cocoa flavanols lower vascular arginase activity in human endothelial cells in vitro and in erythrocytes in vivo. Arch Biochem Biophys 2008;476:211-5.

11. Wyrepkowski CC, Costa DL, Sinhorin AP, Vilegas W, De Grandis RA, Resende FA, et al. Characterization and quantification of the compounds of the ethanolic extract from Caesalpinia ferrea stem bark and evaluation of their mutagenic activity. Molecules 2014;19:16039-57.

12. Ambarwati NS, Malik A, Deborah EA, Arpatism CH, Hanif M, Elya B, et al. The antibacterial activity of fractions of ethyl acetate Garcinia latissima Miq. stem bark extracts against Bacillus subtilis and Pseudomonas aeruginosa. Asian J Pharm Clin Res 2017;10:69-72.

13. Steppan J, Nyhan D, Berkowitz DE. Development of novel arginase inhibitors for therapy of endothelial dysfunction. Front Immunol 2013;4:278

14. Sauriasari R, Azizah N, Basah K. Tyrosinase inhibition, 2,2-diphenyl1-picrylhydrazyl radical scavenging activity, and phytochemical screening of fractions and ethanol extract from leaves and stem bark of matoa (Pometia pinnata). Asian J Pharm Clin Res 2017;10:85-9.

15. Wang L, Weller C. Recent advances in extraction of nutraceuticals from plants. Trends Food Sci Technol 2006;17:300-12.

16. Slimani A, Abdellah M, Hamadi L. Phytochemical screening, contribution to the study of the antifungal effect of flavonoids from different parts of Ziziphus lotus of South-West Algeria. Asian J Pharm Clin Res 2017;10:13-6.

17. Ghasemzadeh A, Jaafar H. Optimization of reflux conditions for total flavonoid and total phenolic extraction and enhanced antioxidant capacity in pandan (Pandanus amaryllifolius Roxb.) using response surface methodology. Sci World J 2014;2014:1-10.

18. Tjernberg A, Markova N, Griffiths WJ, Hallén D. DMSO-related effects in protein characterization. J Biomol Screen 2006;11:131-7. 